\title{
DEVELOPING INTERVIEWER PROFICIENCY: A SELF-PERCEPTION SURVEY
}

\author{
Riin Kont-Kontson, Ene Alas, Suliko Liiv
}

\begin{abstract}
The article reports the findings of a survey among 440 teachers of English in Estonia who participate in the oral proficiency interview of the national examination in the English language as interviewers. Examining the results of the questionnaire statement by statement, the study reveals that interviewer behavioural patterns emerge during the interview, some of them threatening its validity.The understanding of interviewer competence is very diverse among the interviewers and the degree to which they adhere to the standards defined for the interviewers of national examination in the English langage in Estonia is sometimes quite low. The interviewers are often unable to separate their role as an interviewer from being a teacher; they transfer their teaching behaviour to the interviewing situation. The teachers have difficulties with identification of appropriate accommodation strategies as well as controlling the extent of interaction between the interviewer and the assessor. The authors suggest a number of interviewer training strategies to combat the problems. ${ }^{*}$
\end{abstract}

Keywords: validity, reliability, interviewer, interviewer training, oral proficiency interview

\section{Introduction}

In 2008, a substantial change was introduced in the oral proficiency interview (OPI) of the national examination in the English language in Estonia, the aim of which was to increase the level of standardisation of the process. The new format envisaged all interviewers using an interview script, which specified the amount of support the interviewer was obliged to give to the candidate during the process of the speaking test and limited the amount of improvisation allowed by the interlocutor. This change was undertaken in order to provide uniform conditions for all candidates during the OPI, thus increasing the validity of the test. In 2009, a survey was carried

* This research has partly been supported by the Estonian Science Foundation Grant No 9037. 
out involving 81 teachers who had all participated in the national examination as interviewers, to investigate their responses to the new format. The main finding of the study was a disparity among the interviewers in terms of understanding the interviewer's role during the OPI as well as their confidence level, their attitude to the interviewer script and their overall professionalism during the interviewing process (cf. Alas 2010: 109, for the results see Alas 2010: 75-109). A clear outcome of the study was a need for further interviewer training. As the 2009 survey was carried out barely a year after the new format was introduced, a new study was deemed necessary to make more informed decisions about training needs. Since the interviewers' perception of their own interviewing practices is an important part of those decisions, the current study aims to investigate the interviewers' selfevaluation. It also involves significantly more people (440) in order for the results to be more generalizable and reliable. Interviewer proficiency can be defined in terms of the interviewer's language proficiency, which may vary as the target group is comprised of non-native speakers with diverse foreign language learning experience and exposure to the English language. This aspect of interviewer proficiency was not investigated in the current study. Instead, interviewer proficiency was interpreted as the participants' ability to conduct OPIs in a systematic and efficient manner, adhering to the interviewer script and general guidelines for interviewer behaviour which all participants had been trained to do.

\section{Materials and methods}

The research was conducted using both quantitative and qualitative methods of analysis: descriptive, analytical, comparative and statistical methods of study were applied. The survey was compiled in co-operation with the Estonian National Examinations and Qualifications Centre (currently Foundation Innove) and was designed to focus on further training needs for OPI interviewers, i.e. the target group of investigation were the teachers who had already gone through obligatory initial interviewer training and had acted as interviewers during the OPIs of the national examination in the English language. The teachers were asked to respond to eight statements: five open-ended statements and three multiple choice items with an opportunity to add comments.

The first statement (I think I am a competent interviewer because...) is an open-ended question and was intended to disclose the respondent's understanding of what it entails to be a competent interviewer, and accounting for their own estimated level of professionalism. The second statement (I think that proper interviewing atmosphere is... and I achieve this by...), also an open-ended question, may be interpreted as an expectation to comment on either the macroclimate in the examination room over which teachers have little control, e.g. the classroom is too warm or there is too much noise coming from outside, which is often beyond the interviewer's control yet can have an effect on the candidates' performance (construct irrelevant variance). Alternatively, they could comment on the atmosphere created by relations between the interviewer and the student, i.e. microclimate the level of friendliness and rapport, for instance. It was expected that respondents would be aware of both angles of the issue, yet it was still useful to find out if this was so and which of the two was more important. 
Open-ended statements 3 (During the interview, I struggle most with...) and 4 (What annoys me about interviewing is that...) were more tied to the specific problem areas for interviewers and so as not to restrict the respondent, no options were proposed. Previous research had suggested a number of stumbling blocks: interviewer's own language ability (speed of speech, accent), the interview materials (the script, cue cards), time keeping and students' responses to prompts or followup questions (cf. Alas 2010). In addition to that, depending on the personality of the interviewer, they might be annoyed by students who do not say much or who ask questions, or by the procedure itself, because OPI is an unnatural situation to some extent - there is repetition of the same routine irrespective of the number of students or time of the day, which makes interviewing tedious (ibid.). Another aspect related to this question was whether interviewers were able to separate teaching from testing, because it is natural for a teacher to help the student in the classroom, but during the OPI the teacher, now an interviewer, has to behave differently. He/she is deprived of the right to assist with prompting questions unless specified by the script. Question number 7 (During the interview I interact with the assessor in terms of...) was about the interviewer proficiency and professionalism. The question investigated the extent to which the interviewers were aware of the norms of interaction with the examiner, and what format the co-operation took.

There were three multiple-choice statements in the interviewer questionnaire. With statement number 5 (When the student does not understand me, I use the following accommodation strategies), the interviewers had to circle either a 'yes' or a 'no' after the options. The accommodation options listed were some of the most common accommodation strategies listed in OPI research (cf. Ross, Bervick 1992, Lazarton 1996). The respondents could also add any other techniques if they wished. In statement 6 (The script is...), the respondents needed to comment on the quality and usefulness of the script (helpful/unhelpful, clear/unclear, too detailed/ detailed enough/not detailed enough, easy to use/confusing, other comments). They had to select the appropriate ones from the given options and add qualities if necessary. The final statement, number 8 (Useful formats for further interviewer training would be ...), investigates the usefulness of particular interviewer training formats. A choice was given between evaluating the interviews of other interviewers, listening to and evaluating the respondent's own interviews, getting comments about the respondent's interviews from a trainer, and getting comments about the respondent's interviews from a colleague, with a request to specify any other.

In the final part of the questionnaire, the interviewers had to give some information about themselves; their workplace, length of service as an interviewer and as an English teacher, and their gender. Inserting one's name was optional in the hope that by remaining anonymous the respondents would be more honest and straightforward with their answers.

The results were analysed by first numbering the questionnaires, after which a Microsoft Excel file was created, where the results of each interview were entered. The results were processed, presented as descriptive statistics (including absolute frequencies and mean value) and summarised in tables and graphs. 


\section{Results}

A total of 487 questionnaires were handed out to the English language teachers of Estonia, 485 responded to these questionnaires, and for the purpose of this research 440 answer sheets could be used. The completed questionnaires qualified as data if the respondent had been an interviewer for at least one year and had answered at least two questions. Forty-five questionnaires were discarded because they did not meet these criteria.

Analysing the respondents' experience as interviewers and teachers, it can be said that the longest service was by an interviewer who had worked as a teacher for 50 years, the shortest for one year, and the mean was 21 years. The longest service as an interviewer was as long as the OPI has been used in the English language national examination, i.e. 17 years, the shortest was one year, the mean was nine years. The majority of respondents were female non-native speakers. There were only 22 male respondents out of 440, and due to this imbalance the results were not analysed from a gender perspective. Also, many people gave more than one answer to the statements. This meant that one examiner could be found in two or more results for those statements, e.g. if a statement with four possible options has been answered by 440 people and each of them had marked every given option, then there were altogether 1760 responses, i.e. more than the number of the interviewers involved in the study.

Next, the survey results will be discussed statement by statement. For the sake of convenience, the statements are numbered and referred to in an abbreviated form Q1, Q2, Q3, etc. The results are expressed both in the form of figures and discussion.

The information in Figures 1 to 5 and 11 should be read as follows: the vertical axis of the figure shows the potential number of participants, the horizontal axis shows the actual number of particular participant answers. The numbers on the columns show how many people gave the same answer. The percentage on the right margin shows the proportion of the participants. The comments on the right are the most popular answers of the current statement.

\subsection{Statement Q1. I think I am a competent interviewer because...}

The responses given to the first statement are summarised in Figure 1.

Statement Q1 received responses from 433 teachers out of 440. The most common result, given by $55 \%$ of the teachers, is that they are competent interviewers because they have been interviewing for years. The next largest group (23\%) considered attending training courses the reason for being a professional examiner; $16 \%$ see the key to competence in knowing the procedure, following the script and the exam requirements, and $14 \%$ in being competent and experienced, giving a rather circular answer, which is hard to interpret. A further $10 \%$ of the interviewers believe that their encouraging, supportive, friendly and calming attitude makes them competent interviewers, which is an important aspect but insufficient without procedural rigour. Just 25 teachers (6\%) consider their teaching experience enough to be competent when interviewing. This implies that teachers sometimes equate teaching skills with testing skills. 
I think I am a competent interviewer because

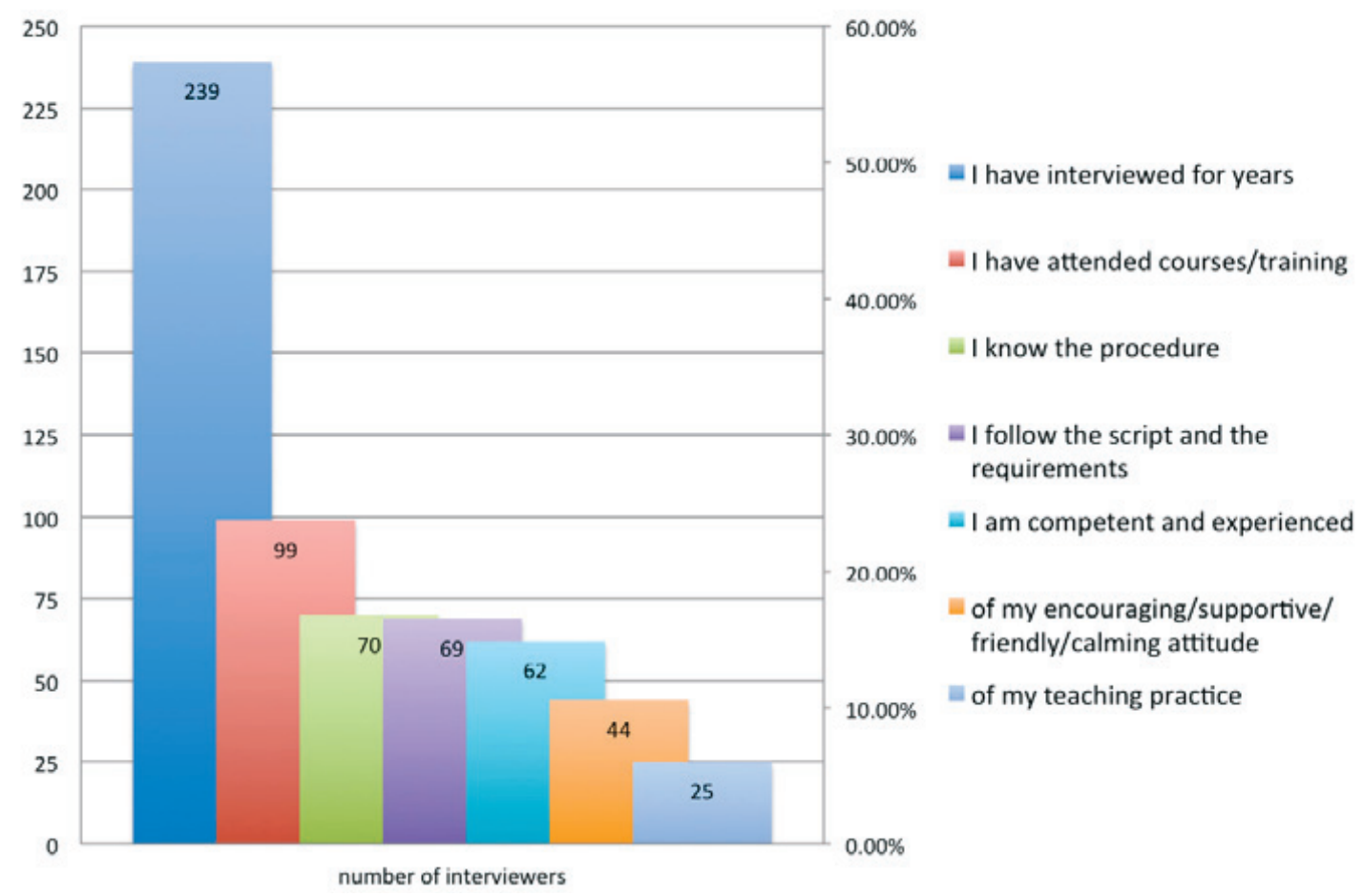

Figure 1. Responses to Q1

There are some other opinions given which illustrate the respondents' concept of interviewer competence, but are too few to be considered significant although they are quite revealing. Five teachers consider themselves competent interviewers because they analyse their mistakes afterwards and try to be as objective as possible treating everyone in the same way; one respondent thinks that he/she is competent because he/she has seen other teachers interviewing, and worked in the team who prepared the first speaking exam.

The survey reveals that if people have been interviewing for a long time, e.g. since the introduction of the OPI in the speaking part of the English language national exam and they know and follow the exam procedure, they believe that it qualifies them as competent interviewers. Both Brown (2003) and Fulcher (2010) seem to suggest that is only partly so: time does give experience, but there is more to language testing and to interviewing skills than spending time interviewing and knowing the theory. However many times one has interviewed, if it is not done meticulously and in a standardised manner, time alone is not going to guarantee that one would be a more competent interviewer. Brown says that the styles of the interviewers may become so diverse over time that they are leading to different outcomes for the students (2003: 17), therefore regular training is needed. But training alone is not enough - the knowledge that one gains through different courses and workshops should be actively practised in order to acquire the skills needed to become a more experienced and competent interviewer. 


\subsection{Statement Q2.1. I think that proper interviewing atmosphere is...}

Figure 2 presents the results given to the first part of the second statement:

I think that proper interviewing atmosphere is

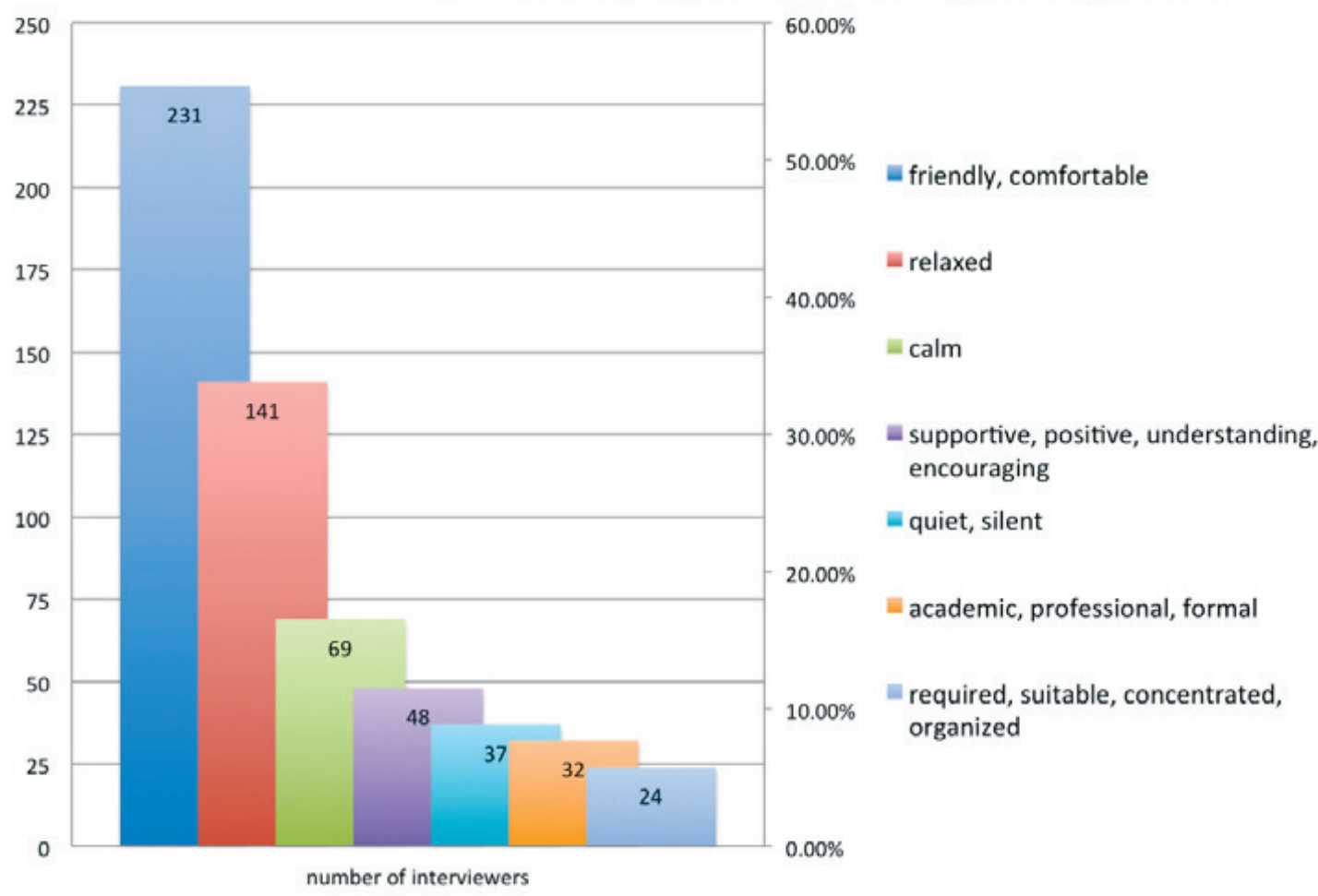

Figure 2. Responses to Q2.1

Q2.1 was answered by 415 respondents. Of these, $56 \%$ believe that the atmosphere has to be friendly and comfortable; $34 \%$ suggested that it should be relaxed and $17 \%$ that it should be calm. A further $12 \%$ consider a proper interviewing atmosphere is supportive, positive, understanding and encouraging; $9 \%$ quiet and silent; $7 \%$ find the proper interviewing atmosphere to be academic, professional and formal. The remaining $6 \%$ use fairly vague terms; required, suitable, organized and concentrated. The term 'required' is used to form a rather ambiguous response. It seems to suggest that the teachers are aware that there are requirements to the atmosphere, but they do not specify what they are.

The responses to Q2 seem to focus mainly on the micro-climate, rather than commenting on the atmosphere that is independent of them as interviewers. The outcome demonstrates the teachers' preoccupation with providing an atmosphere where the student can relax and perform in an environment which is as stressfree as possible, so that they can display their best skill level. This is an admirable ambition. At the same time, not emphasising the seriousness of the OPI may lead to invalid results, because if the interviewer spends too much energy on creating a relaxed and positive environment it is possible that the students will not take the process seriously enough and not show their real proficiency levels. Nevertheless, there is still some justification in creating an atmosphere which is not over-formal and academic, which would result in the candidate becoming overly anxious. 


\subsection{Statement Q2.2. And I achieve this by...}

The results given to the second part of the second statement can be seen in Figure 3 .

... and $I$ achieve this by ...

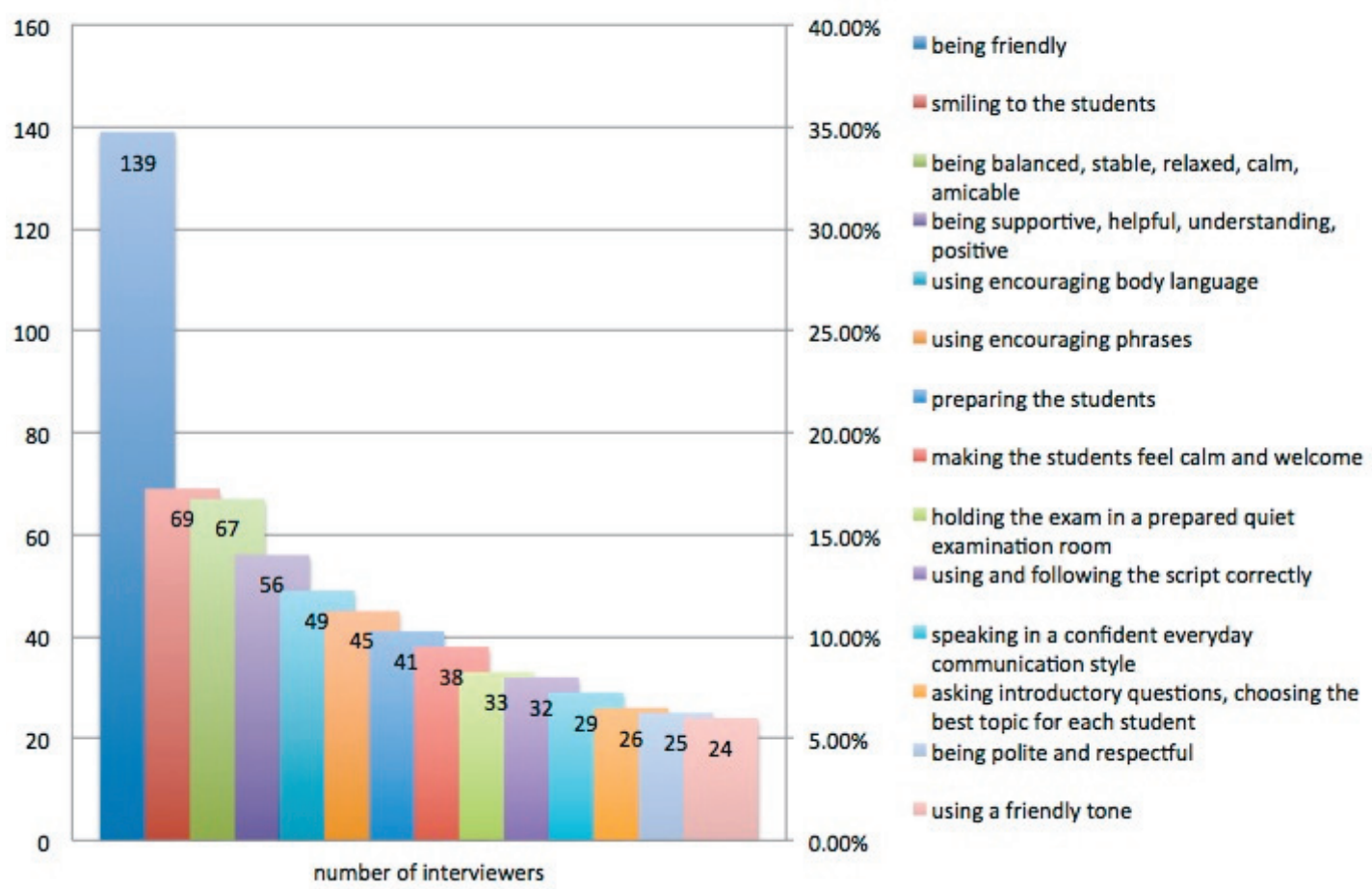

Figure 3. Responses to Q2.2

This statement received 412 responses. About one-third (34\%) think that to achieve the right testing atmosphere they need to act in a friendly manner and $17 \%$ mention smiling to the test-taker. Also, teachers emphasise their own role as models to achieve an anxiety-free atmosphere by saying that they have to be balanced, stable, relaxed, and calm (16\%), and supportive, helpful, understanding and positive (14\%) in order for the atmosphere to be appropriate for the OPI. Some teachers find it very important to use encouraging body language (12\%) and encouraging phrases (11\%), without specifying, however, what they are. Some of the interviewers achieve the appropriate atmosphere by preparing the students(10\%), by making the student feel calm and welcome (9\%), by having the examination in a quiet classroom, and using and following the script correctly (8\%). Speaking in an everyday communication style is considered a key factor for achieving the right atmosphere by $7 \%$, and choosing the best topic for each student, being polite and using a friendly tone by $6 \%$ of the interviewers.

The results of Q2.2 revealed a variety of different strategies ranging from different aspects of body language and adherence to the examination procedure to securing a proper macroclimate in the test venue. It seems that the interviewers concentrated mostly on their own role, although some of the comments - choosing the best topic for a particular candidate or finding a good contact with every testtaker - would need follow-up interviews with the particular respondent to find out what exactly was meant. 


\subsection{Statement Q3. During the interview, I struggle most with...}

The answers given to the third statement are summarised in Figure 4 below.

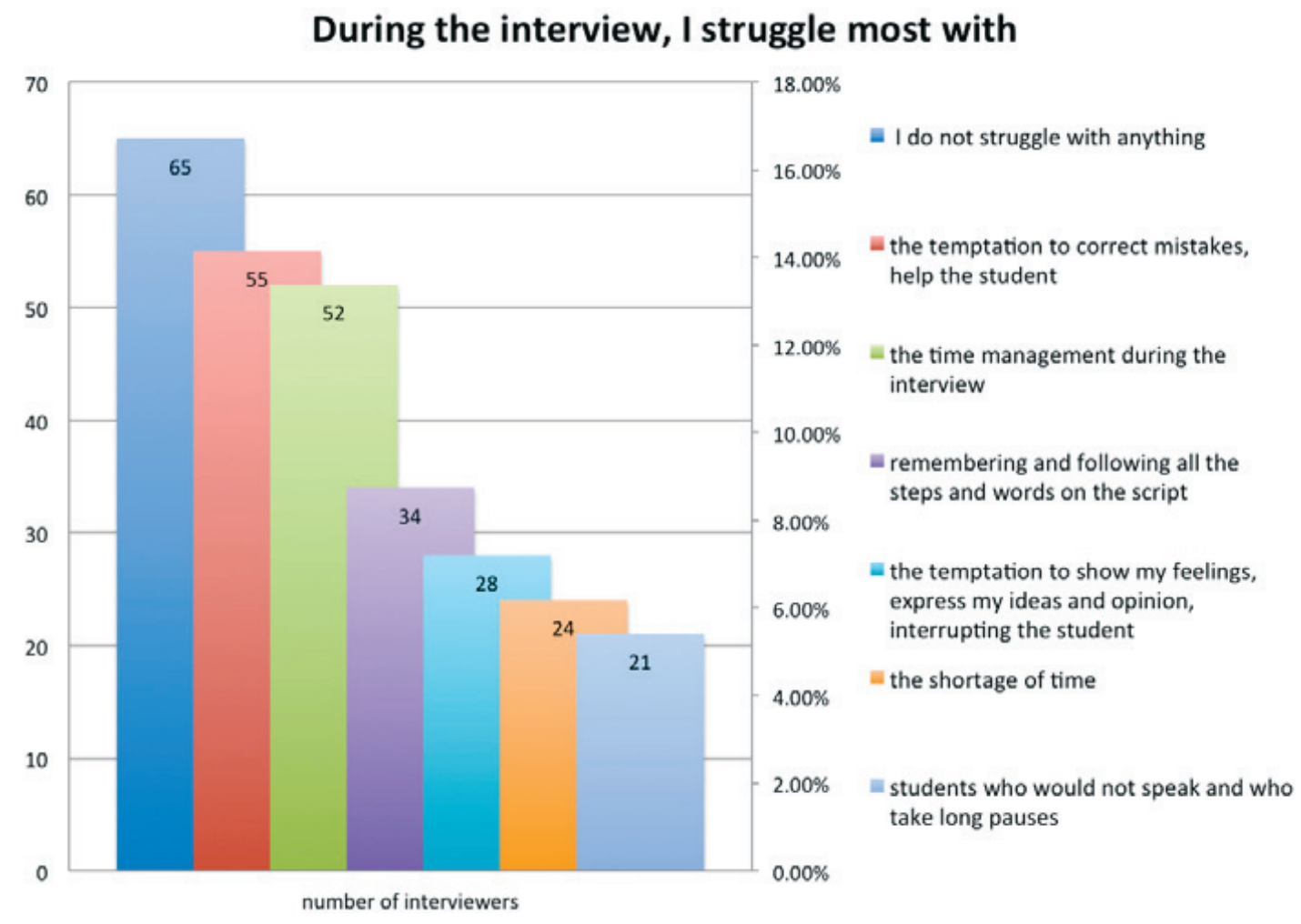

Figure 4. Responses to Q3

There were 396 responses to Q3. Of these, 16\% claimed not to struggle with anything; $14 \%$ admitted to struggling with the temptation to help the student and correct their mistakes during the OPI; $13 \%$ noted trouble with time management during the interview, and 9\% had difficulties with remembering and following all the steps and phrases in the script. Some of the interviewers fight with the temptation to show feelings (e.g. irritation), express ideas and opinions and interrupt the student (7\%). Shortage of time (6\%) and students who do not speak and take long pauses (5\%) are also matters causing the interviewers to struggle.

The above outcome seems to indicate that the teachers are aware of the difference between their roles in the classroom and in the examination room but they find separating the two sometimes quite hard. Time management and using the scripts also seem to need further practice.

\subsection{Statement Q4. What annoys me about interviewing is that...}

Q4 yielded 391 responses. Of these, 23\% claim not to be annoyed by anything, $8 \%$ dislike the lack of similarity between the OPI and real-life conversation, as everything in the OPI is prescribed, and there is no creativity. Some interviewers say that having to go through the same procedure over and over again for hours is annoying (7\%), especially when there are very many students to interview. Some 
consider the questions and the topics too difficult and confusing, in some cases even too personal (6\%). Some claim that they are annoyed by the fact that they cannot help the student in any way during the OPI (5\%).

What annoys me about interviewing is that

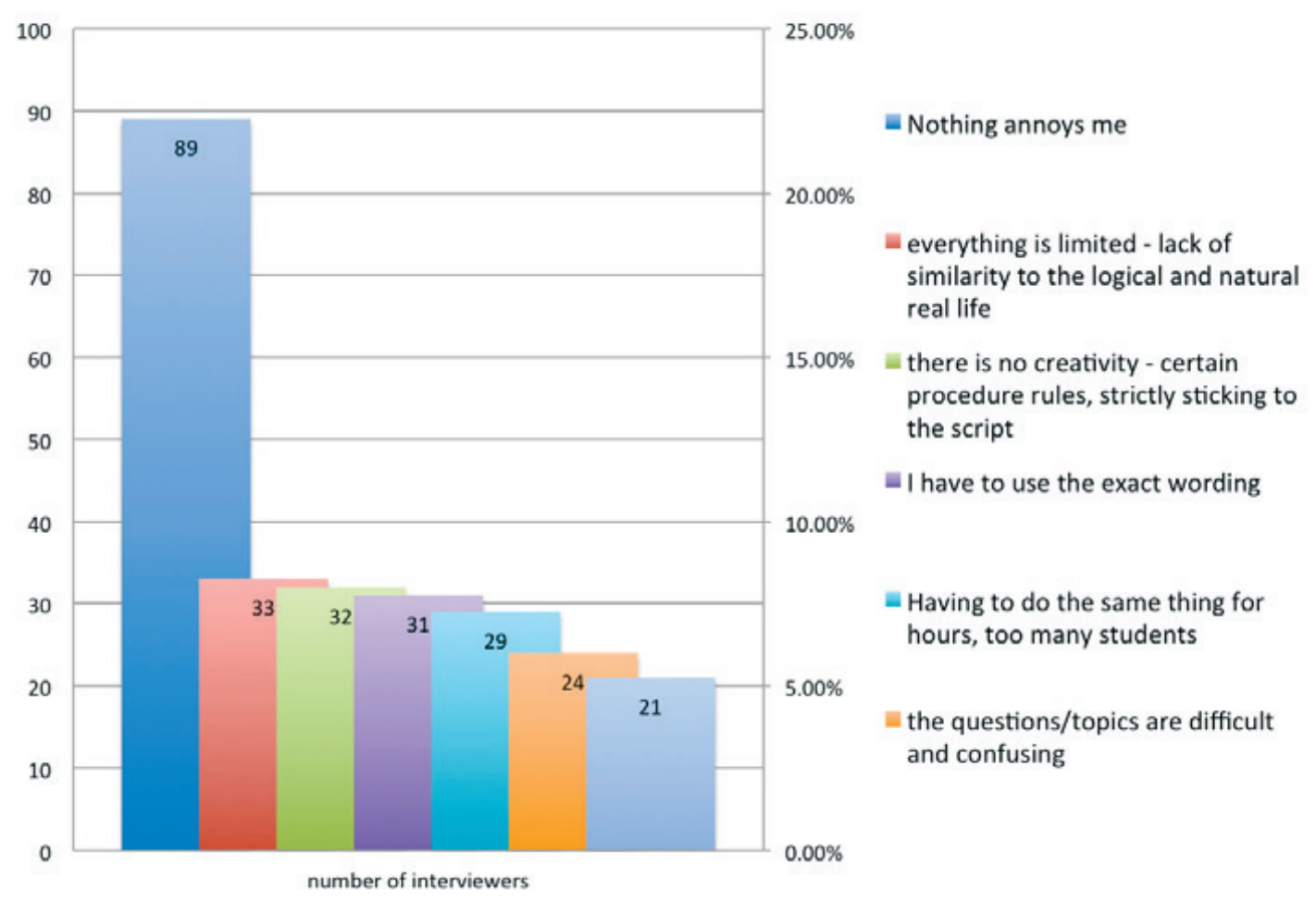

Figure 5. Responses to Q4

The results seem to indicate that although almost a quarter of the respondents are unperturbed by interviewing, but three-quarters of them find something that annoys them about it. Mainly, the respondents were dissatisfied with the script and the procedure itself, not so much with student behaviour or their own behaviour. It is important to sensitise the interviewers to the need to maintaining the examination routine from one interview to the next for the sake of the exam validity.

\subsection{Statement Q5. When the student does not understand me, I use the following accommodation strategies...}

Q5 was answered by 438 respondents. The majority (87\%) of the interviewers said that they use repetition of the question or statement as an accommodation strategy when the students do not understand them. Less frequently used options are pronouncing the question more clearly (79\%), repeating and slowing down the tempo (73\%), giving a synonym for a difficult word (55\%), and paraphrasing the question (54\%). It is interesting that 12 interviewers out of 438 use translating into the candidate's first language (L1) as an accommodation strategy (3\%). This is noteworthy given that translation is an accommodation technique not allowed by the OPI rules. In order to retain fairness in the OPI procedure (Fulcher 2003: 79), accommodation strategies should be the focus of in-service training. The fact that 
none of the 438 respondents could name any additional accommodation techniques in Q5 as requested makes it even more necessary.

\subsection{Statement Q6. The script is...}

Q6 concerned the script. The respondents had to circle particular characteristics six pairs of opposites - and they could add other characteristics if they wished. There were 412 responses to Q6. The answers are summarised in the pie charts below, one characteristic at a time. Every slice shows how many respondents chose a particular answer. The first number shows the exact number of people who chose it, and the second indicates the percentage.

First, the interviewers had to decide if the script was helpful/unhelpful (see Fig. 6):

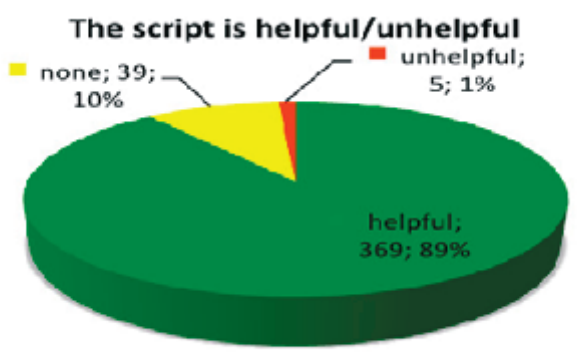

Figure 6. Responses to Q6 - statement a

An overwhelming majority (89\%) found the script to be helpful, $1 \%$ find it to be unhelpful and $10 \%$ cannot decide. It is safe to say that a great majority of interviewers welcome the presence of the script probably because simplifies the OPI procedure.

The second characteristic was clarity (see Fig. 7):

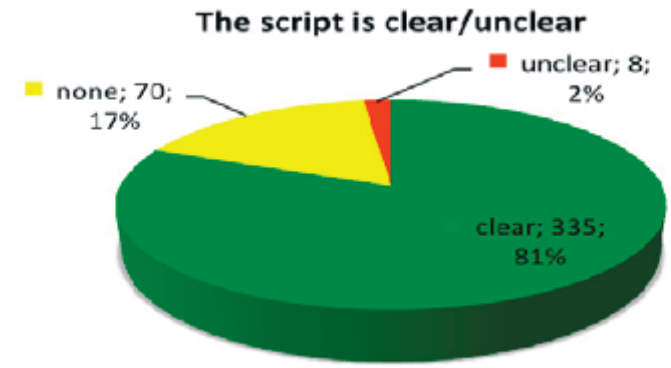

Figure 7. Responses to Q6 - statement b

Again an overwhelming majority (81\%) report the script to be clear and $2 \%$ claim it to be unclear with $17 \%$ undecided. It becomes evident that the majority can understand the script and use it for its intended purpose, but it would be still interesting to know what the $2 \%$ find unclear and why 70 of the respondents could not make up their minds.

The third characteristic investigated is the degree of detail of the script (see Fig. 8): 


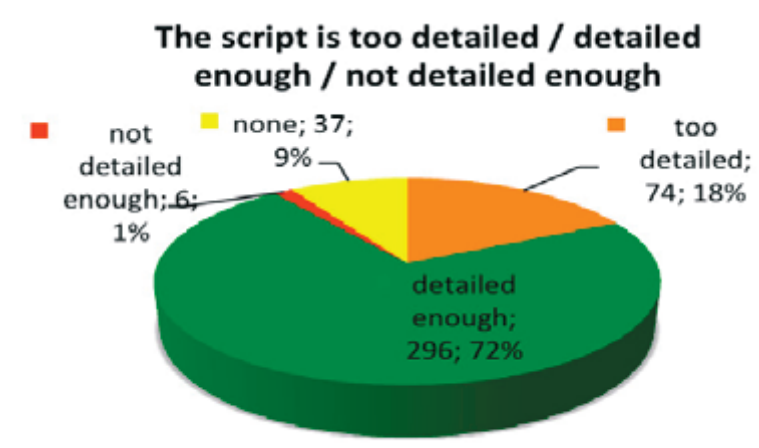

Figure 8. Responses to Q6 - statement c

Nearly three-quarters of respondents to Q6c (72\%) consider the script to be detailed enough, $1 \%$ do not find it detailed enough, $18 \%$ say that it is too detailed and $9 \%$ were undecided. One might speculate here that the issue of detail is perhaps connected to the proficiency and time management skills, because if an interviewer is struggling with keeping time, there may actually be too much information to grasp. It can also be connected to wishing for freedom of action during the OPI. The six people who see it as not detailed enough may need additional help interpreting and managing the script.

The fourth characteristic pertains to the ease of use (see Fig. 9):

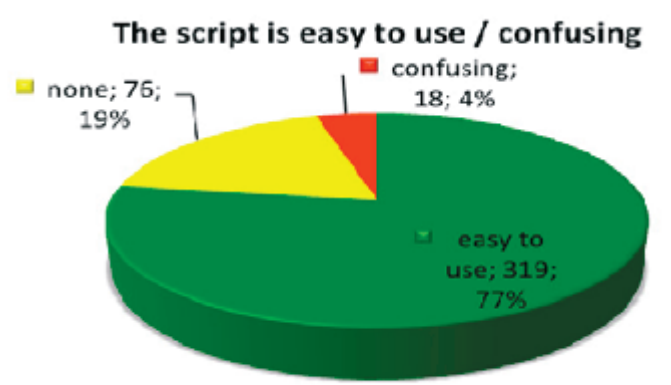

Figure 9. Responses to Q6 - statement d

The majority (77\%) find the script easy to use, $4 \%$ note that it is confusing and $19 \%$ of the interviewers have not responded to this statement. One can only speculate as to what the confusing aspects might be: script wording, script formatting, cue card content. Some light is shed in the final section of the statement where the respondents have provided comments: there have been grammar and logic mistakes on the teachers' cards, the script is too restricting for the interviewer, which means that the situation is unnatural, some topics are unsuitable for children who live in the countryside (e.g. various places for eating out). All the above suggest that practice is needed in working with the script. Another idea might be to recruit more assistance from teachers with item writing. 


\subsection{Statement Q7. During the interview I interact with the assessor in terms of...}

The answers are summarised in Figure 10.

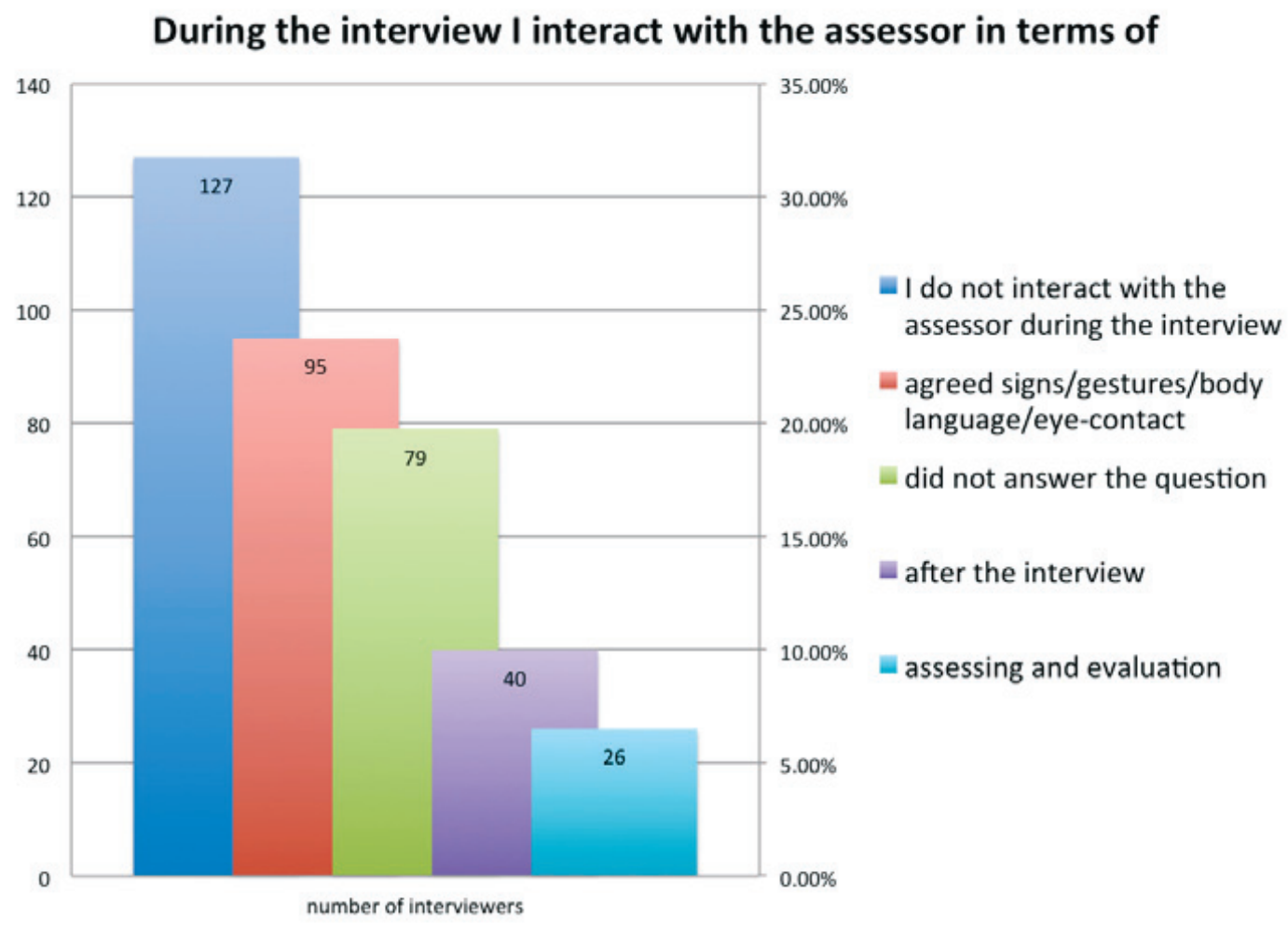

Figure 10. Responses to $Q 7$

Perhaps one of the most intriguing sections of the questionnaire is Q7, requiring information about the interviewer-assessor relationship during the OPI. This is because the script of the OPI does not envisage the interviewer engaging in any discussion or talking to the assessor at all, but the answers to Q7 point to a different situation. Out of the 361 interviewers who answered Q7: 35\% claim not to interact with the assessor during the interview; 26\% say they interact using agreed signs, gestures, body language, and eye contact, without specifying the reasons; $7 \%$ simply report that they interact during assessment. This is a threat to the validity of the result of the OPI, because although the interviewer may know the proficiency level of the test-taker, his/her task as an interviewer detracts from the marking process. The interviewer has to ensure a smooth flow of the OPI, s/he has neither the marking scale nor the time to concentrate on evaluation. This is why there is a third party (assessor) added to the procedure of the OPI. A large number of interviewers (79; $18 \%$ ) did not provide an answer to Q7. One can only speculate about the reason for this. If the respondents left it blank due to the fact that they do not interact with the assessor during the OPI, and they just did not feel it necessary to indicate it, then it would be a positive result. But if Q7 is not answered because they do not want to reveal that they interact with assessors, then therein lies a threat to the test validity as discussed above.

There were other serious deviations described involving interacting with the assessor. They were too few to be significant but are still interesting from the point of 
view of the current study: eight interviewers said they gave the general impression to the assessor and discussed the student's mistakes; four reported giving background information about the student's proficiency in English. One interviewer asked the assessor if he or she would need more data to evaluate the student's performance and offered to prolong the interview, others interacted with the assessor by suggesting extra help that can be offered to the student. These strategies seriously undermine the validity of assessment and these interviewers should be eliminated from the process of measuring the students' oral proficiency. Further training is needed to focus on this problem fairly urgently.

\subsection{Statement Q8. Useful formats for further interviewer training would be...}

This question asked the interviewers to point out useful formats from the given options and 433 did so. The vast majority (86\%) consider evaluating the interviews of other interviewers to be the most useful format, testifying to their reluctance of being subjected to criticism themselves; $62 \%$ would like to get comments about their interview from colleagues; $53 \%$ would like to get feedback from a trainer. Less than half (44\%) believe that a useful format for further training would be listening to and evaluating their own interviews, and 33\% say they would not like that. The final part of Q8 asked the respondents to specify other useful formats, and it became evident that listening to, commenting on and evaluating sample videos would be the best training methods. The respondents also suggest sending training materials to schools and getting comments from the students. But also there are a few respondents who cannot understand why obligatory courses for interviewers take place so often, claiming that the teachers of the English language are already feeling over-trained. What the interviewers may fail to understand is that, as the field of language testing is fairly young, improvements are frequently offered and everyone connected to the field needs to be aware of the changes. Also, the effects of training are not very long-lasting and thus need refreshing (cf. Fulcher 2003: 260).

The data demonstrates a notable deviation among the interviewers regarding acceptable interviewer behaviour as well as expectations regarding further training. The following section will try to make some suggestions for the latter in order to reduce the variation.

\section{Implications of the survey for interviewer training}

The analysis of the survey responses exposes a number of issues that interviewer training needs to address. First, the understanding of the concept of interviewer competence is very diverse among the teachers. In future training, it seems to be important to focus on the discussion of the essence of professionalism, what its different aspects are and how interviewers interpret them. Thus the training needs to give a theoretical background to interviewers' behaviour.

Next, interviewers appeared to struggle with a variety of aspects of OPI, especially with the temptation to assist students. This implies that the interviewers struggle to differentiate between their role as an OPI interviewer and that of a 
language teacher. In terms of training, it is again necessary first to further explain the differences between these two roles, together with watching videos of good and bad interviewer practice. Checklists of critical points of behaviour could be implemented as a while-watching tool, which would make both the while-watching evaluation and also the post-watching discussion more focused. The discussion could then be followed by video recording the trainees' own behaviour during a simulation OPI with volunteer student participants and analysing it afterwards, utilising the same checklists. This could be arranged either as a peer-to-peer activity or as a feedback session from an interviewer trainer.

A sub-problem, frequently encountered in Estonia in the context of testing English language speaking skills, related to the urge to help students. This arises when the student does not understand the interviewer and is silent or gives too brief an answer. Here, the interviewer has to master the strategies available to him/her that can be used to provoke a student to say more, e.g. making sure s/he allows for a 5-second silence and does not 'jump in' too fast; asking the student explicitly if s/ he has anything else to say, etc.). If the silence on the part of the student continues, the interviewer will have to refrain from attempts at further assistance (which can be quite frustrating) and move on to the next question/task.

A problem that needs continuous attention is the respondents' dissatisfaction and struggle with the script and the interviewer's cue card and the interviewing procedure itself, more precisely its rigid nature. In training, the interviewers may need to be reminded of the reasons why the OPI uses a standard procedure, and why deviations pose a threat to validity. The script would need a more thorough explanation from the point of view of how it functions and what may happen if the interviewees receive different treatment, i.e. when there are deviations from the script. This means in-service training in the principles of language testing. Understanding of the mechanism of cue card functioning can be trained by involving teachers in item writing, which in the Estonian context would mean developing statements for the monologue as well as role plays.

Responses to Q5 suggest that it is necessary to build the interviewers' awareness about accommodation strategies - to explain to them what accommodation strategies are and what kind of variety there is for the teachers to use. To begin with, it is important to give a theoretical background to accommodating behaviours and explain what types of accommodating behaviours people usually engage in interaction. It is also necessary to discuss accommodation in a teaching and a testing situation. There are particular accommodation techniques that the OPI procedural rules do not allow. For example, slowing down the tempo, reiteration and paraphrase of a word are acceptable techniques, whereas translation into one's first language is not. As the OPI is attempting to replicate a foreign language interaction situation in a foreign setting, where it would be fairly unlikely to find a person who could translate the unknown word/expression into Estonian, the interlocutors should be able to use other accommodation techniques. So when an interviewer uses translation, s/he might be giving certain students an advantage, which is not fair to other students who are taking the same examination with a different teacher who does not use translation as an accommodation technique.

A very common concern was time management problems during the OPI. Differences in the amount of time given for preparation for tasks as well as task 
performance will affect the comparability of the exam results and consequently exam reliability/validity. The responsibility for training should be assumed by the teachers themselves. Practicing interviewing outside examination time in the classroom gives teachers the possibility to improve their skill of interviewing. It would also give the students necessary experience regarding the time available for task preparation and task delivery on the examination day. Recording one's own interviews and analysing them can give a better idea of one's behaviour in this respect during the OPI as well.

It would be beneficial to go through the requirements set for the interviewers (a document provided by the examining body), especially where the dos and don'ts have been explained in detail. The teachers might benefit from being aware of the fact that studies by Morton et al. (1997) and McNamara and Lumley (1997) both found that the assessors inflate their rating of the candidate when they perceived the interviewer to be less than competent during the interview, i.e. the interviewer's behaviour has an impact on the reliability/validity of the exam results.

Teachers need feedback on their own behaviour as interviewers; without that, no improvement can take place in the quality of the OPI. As was pointed out above, feedback can be obtained at least in two different ways: the teachers could record their own interviews, not only those taking place during the examination session, but during examination preparation time as well. Another option would be arranging training courses in order for the recordings to be analysed by trainers. Getting an outsider's perspective of the conduct of interviews can be quite useful in revealing practices that the interviewers may have failed to notice themselves.

Also, recording of the OPI should be compulsory and not, as is the case hitherto, a choice for the student to make. It is certainly important from the point of view of a more valid assessment, but from the interviewers' point of view, it may have a disciplining influence because when the interviewers are aware that there is a chance that their work may be checked, they will be more meticulous and abide by the requirements more seriously. This will mean a more standardised approach towards the process and consequently a more valid exam.

\section{Conclusion}

The aim of this paper was to study interviewers' perceptions of their roles during the management of the OPI with a view to deciding potential training needs for interviewers. In order to increase the validity of the OPI through improving interviewer behaviour, the current study, having pinpointed problematic areas that need to be dealt with in interviewer training, established general directions for further training. The main goals here should be awareness building and practice of various aspects of the OPI.

A considerable amount of work needs to be done in training the interviewers to understand what aspects of their conduct need improvement, and what they themselves can do in order to increase their professionalism as interviewers. 


\section{References}

Alas, Ene 2010. The English Language National Examination Validity Defined by Its Oral Proficiency Interview Interlocutor Behaviour. Tallinn University Dissertations on Humanities 22. Tallinn: Tallinn University Press.

Brown, Annie 2003. Interviewer variation and the co-construction of speaking proficiency.Language Testing, 20 (1), 1-25. http://dx.doi.org/10.1191/0265532203lt2420a

Fulcher, Glenn 2003. Testing Second Language Speaking. London: Pearson.

Fulcher, Glenn 2010. Practical Language Testing. London: Hodder Education.

Lazarton, Anne 1996. Interlocutor support in oral proficiency interviews: The case of CASE. Language Testing, 13 (2), 151-172. http://dx.doi.org/10.1177/026553229601300202

McNamara, Tim; Lumley, Tom 1997. The effect of interlocutor and assessment mode variables in overseas assessment of speaking skills in occupational settings. - Language Testing, 14 (2), 140-156. http://dx.doi.org/10.1177/026553229701400202

Morton, Janne; Wigglesworth, Gillian; Wiliams, Donna 1997. Approaches to the evaluation of the interviewer performance in oral interaction tests. - G. Brindley, G. Wiggleworth (Eds.). Access: Issues in English Language Test Design and Delivery. Sidney: National Centre for English Language Teaching and Research, 175-196.

Ross, Steven; Berwick, Richard 1992. The discourse of accommodation in oral proficiency interviews. - Studies in Second Language Acquisition, 14 (2), 159-176. http://dx.doi. org/10.1017/So272263100010809

Riin Kont-Kontson on tegevõpetaja ja inglise keele riigieksami intervjueerija. riinkk@gmail.com

Ene Alase (Tallinna Ülikool) teadushuvid on keeletestimine, testide koostamine ja nende kvaliteedi hindamine, õpetajakoolitus, õppekirjanduse hindamine.

ene.alas@tlu.ee

Suliko Liivi (Tallinna Ülikool) uurimisvaldkonnad on kontrastiivuuringud, kultuuridevaheline suhtluspädevus, keelepoliitika, võõrkeelte õpetamise metoodika, testimine.

liiv@tlu.ee 


\section{INTERVJUEERIJA KUTSEMEISTERLIKKUST ARENDADES: ANKEETKÜSITLUSE TULEMUSTE ANALÜŨS}

\section{Riin Kont-Kontson, Ene Alas, Suliko Liiv}

Tallinna Ülikool

Uurimuse käigus küsitleti 440 inglise keele õpetajat. Ankeetküsitluse eesmärgiks oli välja selgitada suulist keelepädevustesti läbiviivate intervjueerijate sellised käitumismustrid, mis võiksid vähendada inglise keele riigieksami tulemuste valiidsust ning mille põhjal oleks võimalik intervjueerijate koolitusi planeerida. Uurimus näitas, et intervjueerijate arusaam oma kutsestandardist varieerub märkimisväärselt. Intervjueerijad ei suuda sageli eristada enda kui õpetaja ja enda kui intervjueerija rolle, ei valda sobivaid kohandumustehnikaid ega tunne intervjueerija ja hindaja vahelise suhtlemise protokolli. Nende probleemide lahendamiseks esitatakse artiklis mitmeid vajalikke koolitusstrateegiaid.

Võtmesõnad: testimine, valiidsus, intervjueerija kutsemeisterlikkus 